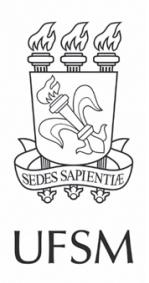

\title{
Artigos
}

\section{Intensidade da irradiância no fluxo e alocação do carbono em árvores adultas de três morfotipos de Paubrasilia echinata}

\author{
Irradiance intensity in carbon flow and allocation in adult trees of three \\ morphotypes of Paubrasilia echinata
}

\author{
Carlos Augusto Pagotto Martins ${ }^{\odot}$ \\ Vinicius Novo Gama'• \\ Fabiano Caprini Volponi' ${ }^{\oplus}$ \\ Bernardo Pretti Becacici Macieira' ${ }^{\oplus}$ \\ Geraldo Rogério Faustini Cuzzuo' ${ }^{\oplus}$ \\ 'Universidade Federal do Espírito Santo, Vitória, MG, Brasil
}

\section{RESUMO}

Compreender como a irradiância solar influencia na qualidade fisiológica de árvores adultas de morfotipos de Paubrasilia echinata pode ser útil na definição das estratégias de florestamento desta espécie. Do tronco dessa arbórea se obtém matéria-prima para confecção de instrumentos de corda musical. Neste estudo, analisaram-se o fluxo e a alocação do carbono não estrutural-CNE (açúcares solúveis e amido) e estrutural (celulose, hemiceluloses e lignina) em indivíduos adultos de três morfotipos de Paubrasilia echinata cultivadas na sombra e pleno sol. O pleno sol estimulou o crescimento do caule, a assimilação do $\mathrm{CO}_{2}$, assim como o acúmulo de CNE e lignina em folhas e caule dos três morfotipos. Porém, os morfotipos médio e grande apresentaram maiores valores dessas variáveis. A celulose não variou entre os tratamentos. O pleno sol promoveu maior deposição de hemiceluloses no caule dos morfotipos médio e grande. Sabendo que a lignina e as hemiceluloses proporcionam melhor qualidade da madeira, os morfotipos médio e grande cultivados em pleno sol parecem reunir melhores características para o uso comercial. Mas, dentre esses dois, o morfotipo grande é o mais indicado devido à maior lignificação caulinar.

Palavras-chave: Açúcares solúveis; Fotossíntese; Lignina; Hemiceluloses 


\begin{abstract}
Understanding how solar irradiance influences the physiological quality of adult trees of the Paubrasilia echinata morphotypes may help define the reforestation strategies for this species. From the trunk of this tree, the raw material is obtained for the confection of stringed musical instruments. In this study, the flow of carbon and allocation of non-structural carbon-NSC (soluble sugars and starch) and structural carbon (cellulose, hemicelluloses, and lignin) in adult individuals of three Paubrasilia echinata morphotypes cultivated in the shade and full sun were analyzed. The full sun stimulated the stem growth, the $\mathrm{CO}_{2}$ assimilation, and the NSC and lignin accumulation in the leaves and stem of the three morphotypes. However, the medium and large morphotypes showed higher values of these variables. Cellulose did not vary between treatments. Full sun promoted a more significant deposition of stem hemicelluloses in the medium and large morphotypes. Knowing that lignin and hemicelluloses provide higher wood quality, medium and large morphotypes cultivated in the full sun seem to have better commercial use characteristics. However, the large morphotype is the most suitable among these two due to the greater stem lignification.
\end{abstract}

Keywords: Hemicelluloses; Lignin; Photosynthesis; Soluble sugars

\title{
1 INTRODUÇÃO
}

O plantio de arbóreas nativas está em ascensão nos trópicos. O sucesso desta atividade depende, em grande parte, do conhecimento das respostas de assimilação e alocação do carbono das espécies de interesse florestal em relação à irradiância solar. Em florestas tropicais, a quantidade da irradiância exigida pelas espécies florestais pode diferir em nível interespecífico e até mesmo dentro da espécie. Uma espécie tropical que apresenta variação intraespecífica no hábito em relação à luminosidade é Paubrasilia echinata Lam. - Gagnon, H. C. Lima e G. P. Lewis, conhecida popularmente como pau-brasil.

Paubrasilia echinata é uma das espécies nativas tropicais de grande interesse para o florestamento em território brasileiro. De seu cerne são confeccionados instrumentos musicais de corda de elevada qualidade certificada pela ressonância e durabilidade de sua madeira (ANGYALOSSY; AMANO; ALVES, 2005). Nativa da Mata Atlântica, essa arbórea possui variações intraespecíficas que divergem entre si na morfologia foliar, coloração do cerne (JUCHUM et al., 2008) e hábito em relação à luminosidade na fase inicial do crescimento (GAMA et al., 2019). O morfotipo pequeno (cerne laranja) é ombrófilo ou tolerante à sombra (MENGARDA et al., 2009), 
enquanto os morfotipos médio (cerne vermelho) e grande (cerne vermelho-escuro) são heliófilos ou tolerantes ao pleno sol (CUZZUOL et al., 2020).

Os critérios de classificação dos hábitos dos morfotipos de pau-brasil consistem na identificação da intensidade da irradiânciafotossinteticamente ativa (sombra ou pleno sol) que ofereça melhor condição ao crescimento e fotossíntese na fase de crescimento inicial. No entanto, extrapolar os resultados da fase de crescimento inicial para a fase adulta pode ser arbitrária, pois profundas mudanças fisiológicas e estruturais podem ocorrer ao longo da ontogenia (SOUZA; VÁLIO, 2003). Como constatado por Zani et al. (2017), o espessamento das células do mesófilo e da parede celular do caule do morfotipo médio de Paubrasilia echinata, com o avanço da ontogenia, parece ser resultado do aumento da intensidade da irradiância. Quanto à fotossíntese, nada se sabe sobre a conservação ou não dos hábitos ecológicos dos morfotipos de pau-brasil da fase juvenil até a fase adulta. De qualquer modo, sabe-se que o hábito ombrófilo e a fotossíntese diminuem com o aumento em estatura das árvores (SENDALL; LUSK; REICH, 2015). Isso ocorre porque à medida que as árvores crescem os requerimentos de luz aumentam em função da demanda de fotossintatos para construção dos tecidos de sustentação (LUSK et al., 2008).

Tais alterações estruturais e fisiológicas em função da intensidade da irradiância parecem ter relação com a capacidade de assimilação e alocação do carbono (MARTÍNEZ-VILALTA et al., 2016). O carbono excedente das necessidades imediatas da respiração celular e crescimento é estocado na forma de reservatórios de carbono não estrutural-CNE (açúcares solúveis e amido) e estrutural como polímeros de parede celular-PPC (celulose, hemiceluloses e lignina) (MARTíNEZ-VILALTA et al., 2016).

Devido a sua ação como sinalizador das variações ambientais (LI et al., 2016; LIU et al., 2017), os açúcares solúveis (mono-, di-, tri- e oligossacarídeos) agem como mensageiros da regulação da biomassa (MARTíNEZ-VILALTA et al., 2016) sendo reconhecidos como componentes-chave na modelagem de árvores (MCDOWELL; FISHER; XU, 2013; RICHARDSON et al., 2013). Em algumas arbóreas tropicais tolerantes à sombra, os açúcares solúveis acumulam em folhas quando expostas ao pleno sol onde parecem exercer a função de osmorregulação e controle do metabolismo 
oxidativo (MENGARDA et al., 2012; GABURRO et al., 2015; PORTELA et al., 2019).

Reconhecida como o maior reservatório de carbono da biomassa vegetal, a parede celular está associada à arquitetura vegetal e qualidade da madeira (CARPITA; MCCANN, 2000; MARTíNEZ-VILALTA et al., 2016). Nesse aspecto, a dureza do tronco de arbóreas tropicais não ombrófilas ou tolerantes à sombra é determinada pela maior proporção dos PPC (MACIEIRA et al., 2020). A celulose e as hemiceluloses são polímeros lineares e reconhecidos como os polissacarídeos mais abundantes da parede celular (CARPITA; MCCANN, 2000). O primeiro polissacarídeo é constituído por unidades de glicose unidas entre si por ligação $\beta(1 \rightarrow 4)$ e o segundo é heterogêneo dividido em quatro classes: xilanos, xiloglucanos, mananos e $\beta$-glucanos de ligação mista (EBRINGEROVA; HROMADKOVA; HEINZE, 2005). Esses dois PPC têm sido bastante investigados em plantas sob estresse hídrico, salino, térmico e aumento de $\mathrm{CO}_{2}$ e radiação ultravioleta. Em relação à intensidade da irradiânciasolar, o desconhecimento é total (LE GALL et al., 2015). A lignina é um polímero fenólico não linear depositado especialmente na parede secundária. Sua deposição é estimulada pelo aumento da irradiância solar em algumas lenhosas (LE GALL et al., 2015; CESARINO, 2019) e com o avanço da ontogenia (ZANI et al., 2017).

Compreender como a irradiância interage com a fotossíntese e alocação de carbono em plantas adultas dos morfotipos de Paubrasilia echinata pode ser útil na definição das estratégias de florestamento desta espécie. Particularmente, quando o interesse maior está na qualidade da madeira. Baseando-se nas diferenças dos hábitos ecológicos dos morfotipos de Paubrasilia echinata na fase de crescimento inicial espera-se que plantas adultas dos morfotipos tolerantes ao pleno sol (morfotipos médio e grande) expressem maior crescimento, atividade fotossintética e tamanho dos reservatórios de carbono não estrutural e estrutural (com destaque para a lignina) em pleno sol. E que o contrário aconteça com o morfotipo tolerante à sombra (morfotipo pequeno) nesta condição. Este trabalho foi desenvolvido com o objetivo de comparar as variáveis das trocas gasosas, crescimento e o tamanho dos reservatórios de carbono em árvores adultas de três morfotipos de Paubrasilia echinata sob pleno sol e sombra. 


\section{MATERIAIS E MÉTODOS}

\subsection{Desenho experimental}

Mudas dos morfotipos pequeno, médio e grande de Paubrasilia echinata (Lam.) Gagnon, H. C. Lima e G. P. Lewis foram propagadas de forma seminal. As sementes foram fornecidas pela Fundação Nacional do Pau-brasil, Recife-PE (1447'21"S e 39¹6'40"O). A produção de mudas foi realizada no viveiro do Instituto Verde Brasil $\left(20^{\circ} 21^{\prime} 50^{\prime \prime} \mathrm{S}\right.$ e $40^{\circ} 39^{\prime} 35^{\prime \prime} \mathrm{O}$ ), Domingos Martins-ES. As sementes foram semeadas em sacos plásticos $3 \mathrm{~L}$ contendo terra e areia (1:1) e mantidas sob tela de polietileno preto (Insulfilm ${ }^{\text {TM }}$, São Paulo, Brasil) onde a irradiância solar correspondeu 50\% da densidade fotossintética do fluxo de fótons-DFFF $\left(900 \pm 170 \mu \mathrm{mol} \mathrm{m}^{-2} \mathrm{~s}^{-1}\right)$ ao meio-dia. Esse valor é a média de sete repetições obtidas em um sensor Quantum (Sky Instruments Ltd., Richmond, Canadá). Irrigação diária com água corrente e por aspersão foi providenciada durante todo o processo de germinação e produção de mudas. A altitude da cidade de Domingos Martins é de 542 metros e o clima da região é Aw tropical de altitude (KÖPPEN, 1948) com temperatura média anual de $21,5^{\circ} \mathrm{C}$. No inverno, a média da temperatura é de $18,5 \pm 4^{\circ} \mathrm{C}$ e a precipitação de $50 \mathrm{~mm}$. No verão, esses valores aumentam para $24 \pm 5^{\circ} \mathrm{Ce}$ $132 \mathrm{~mm}$, respectivamente (dados climáticos fornecidos pela estação meteorológica do Instituto Capixaba de Pesquisa e Extensão Rural em Domingos Martins-ES).

Após um ano de cultivo nas condições acima descritas, 50 plantas sadias e homogêneas ( $15 \pm 4 \mathrm{~cm}$ de altura contendo $5 \pm 2$ folhas) foram plantadas em pleno sol ou $100 \%$ da DFFF $\left(2.500 \pm 170 \mu \mathrm{mol} \mathrm{m}^{-2} \mathrm{~s}^{-1}\right)$ e 50 plantas plantadas no interior de uma floresta secundária, em que a irradiância no estrato inferior correspondeu a 7-15\% da DFFF $\left(150 \pm 40 \mu \mathrm{mol} \mathrm{m}^{-2} \mathrm{~s}^{-1}\right)$. As condições de luminosidade, horário e repetições nos procedimentos de medição da DFFF foram as mesmas adotadas na fase de produção das mudas descritas anteriormente. O plantio foi realizado na área experimental do Instituto Marco Raposo Bows (20²3'02.1"S e 40³8'44.6"O) em Domingos Martins-ES, em espaçamento $3 \times 3 \mathrm{~m}$ entre as mudas, combinando os três morfotipos em arranjo 
misto. O solo da região é do tipo Latossolo Vermelho Amarelo (INSTITUTO CAPIXABA DE PESQUISA E ASSISTÊNCIA TÉCNICA E EXTENSÃO RURAL, 2018). A cova de cada planta recebeu $1 \mathrm{~L}$ de calcário e esterco de galinha (1:3) por ocasião do plantio. Nos meses de pouca chuva, aplicou-se irrigação manual com água corrente, duas vezes por semana. Medidas de altura e diâmetro de 10 indivíduos por morfotipo e tratamento foram realizadas aos 12 anos de idade, concomitantemente com as medições de trocas gasosas e coleta de amostras para as análises de laboratório.

\subsection{Trocas gasosas}

As medições foram realizadas em folhas completamente expandidas e sadias do segundo e terceiro nó apical de ramos basais da copa, em um analisador de gases a infravermelho portátil-IRGA (LI 6400 XT, LI-COR, Lincoln, NE, USA) equipado com fonte de luz vermelha/azul (LI-6400-02B LED). As trocas gasosas foram conduzidas sob luz de saturação artificial de $500 \mu \mathrm{mol}$ de fótons m-2 s-1 para sombra e 1.500 $\mu \mathrm{mol}$ de fótons m-2 s-1 para pleno sol, definidas previamente nas curvas de luz construídas em 12 níveis de irradiância (0 a $1.500 \mu$ mol fótons $\mathrm{m}^{-2} \mathrm{~s}^{-1}$ ) com duração de $60 \mathrm{~s}$ em cada nível de luz. As curvas foram normalizadas ajustando os dados a uma hipérbole retangular modificada de acordo com Lobo et al. (2013). O modelo foi ajustado aos dados usando a análise de regressão não linear (mínimo de diferença quadrática) no Microsoft Solver do Excel (Microsoft Corporation, Redmond, WA, USA) em que o ponto de compensação de luz ( $L C P, \mu$ mol fótons $\mathrm{m}^{-2} \mathrm{~s}^{-1}$ ) e os pontos de saturação de luz (LSP, $\mu$ mol fótons $\mathrm{m}^{-2} \mathrm{~s}^{-1}$ ) foram calculados. A taxa de assimilação líquida do $\mathrm{CO}_{2}(A)$, condutância estomática ao vapor de água (gs), transpiração $(E)$, concentração de $\mathrm{CO}_{2}$ nos espaços intercelulares (Ci) foram medidas entre 08 e 10 horas da manhã sob concentração externa de $400 \mu \mathrm{mol} \mathrm{CO}_{2} \mathrm{~mol}^{-1}$ ar e temperatura média de $23^{\circ} \mathrm{C}$ informados pelo equipamento. Baseado nos dados das trocas gasosas, calculou-se a eficiência do uso da água $(E U A=A / E)$. 


\subsection{Preparo das amostras}

As folhas utilizadas para as trocas gasosas foram removidas para a determinação dos teores dos carboidratos não estruturais e polímeros de parede celular. Amostras do xilema caulinar das plantas adultas foram coletados em 1,5 m acima do solo. Após a remoção da casca (periderme e floema) em uma área $\sim 2 \mathrm{~cm}^{2}$, realizou-se a retirada das amostras do xilema caulinar com um trado manual, em uma profundidade de 5-7 cm da superfície do caule. As amostras de folhas e do caule foram envolvidas, individualmente, em envelopes de papel alumínio etiquetado, acondicionadas em caixa térmica contendo gelo e transportadas para o laboratório onde foi mantido em ultra-freezer $-80^{\circ} \mathrm{C}$. Posteriormente, as amostras foram liofilizadas e pulverizadas em moinho de bola (modelo TE-350, Tecnal, São Paulo, Brasil).

\subsection{Carboidratos não estruturais (CNE)}

Aextração dosaçucaressolúveis(glicose, frutoseesacarose)seguiua metodologia de Pollock (1986). Em 150 mg das amostras pulverizadas foram acrescentados $5 \mathrm{~mL}$ de solução de etanol $80 \%$ e o homogeneizado incubado em banho-maria $80^{\circ} \mathrm{C}$ por 20 minutos sob agitação constante. Em seguida, centrifugado em 10.000 x g por 5 min sob temperatura ambiente $\left(25^{\circ} \mathrm{C} \pm 2\right)$ e reservado o sobrenadante. A operação foi repetida mais três vezes sendo os sobrenadantes reunidos e submetidos ao concentrador de amostras (Tecnal, mod. TE-0194, Piracicaba, Brasil) acoplado ao sistema de injeção por gás de nitrogênio. Os açúcares foram ressuspendidos em 500 $\mu L$ de água ultrapura e as amostras purificadas em filtros Millipore (MillexGV PVDF diâmetro $13 \mathrm{~mm}$, poro $0.22 \mathrm{~mm}$ ). A glicose, frutose e sacarose foram quantificadas por cromatografia de troca aniônica de alta eficiência-HPLC (Shimadzu RID-20A) com detector de refração, coluna CLC-NH 25 cm, fase móvel de acetonitrila 80\%, fluxo de $1 \mathrm{~mL} \mathrm{~min}{ }^{-1}$ e temperatura de $40^{\circ} \mathrm{C}$, utilizando padrões Sigma ${ }^{\circledR}$. A determinação do teor de amido seguiu o protocolo de Amaral et al. (2007) que consistiu em reação com $120 \mathrm{U} \mathrm{mL}^{-1}$ de a-amilase (EC 3.2.1.1) termoestável de Bacillus licheniformis (cód. E-ANAAM, Megazyme, Irlanda), diluída em tampão MOPS 10 mM em pH 6,5 e reação com $30 \mathrm{U} \mathrm{mL}^{-1}$ de amiloglucosidase (EC 3.2.1.3) de Aspergillus niger (cód. 
E-AMGPU, Megazyme, Irlanda) em tampão acetato de sódio $100 \mathrm{mM}$ em pH 4,5. A dosagem do amido foi realizada pela quantificação de glicose liberada no processo de hidrólise do amido e reagido com o corante Glicose PAP Liquiform (Centerlab, Brasil) contendo as enzimas glicose-oxidase $\left(\sim 11,000 \mathrm{U} \mathrm{mL}^{-1}\right)$ e peroxidase $(\sim 700 \mathrm{U}$ $\mathrm{mL}^{-1}$ ), $290 \mu \mathrm{mol} \mathrm{L}{ }^{-1}$ de 4-aminoantipirina e $50 \mathrm{mM}$ de fenol pH 7.5. Após incubação por 15 min a $37^{\circ} \mathrm{C}$, o teor de glicose foi determinado por leitor de microplacas (Thermo Scientific Express Multiskan FC Microplate Photometer, Massachusetts, EUA) em 490 nm. Para a elaboração da curva padrão foi utilizada solução de glicose (Sigma) nas concentrações de 0-12.5 $\mathrm{mg} \mathrm{mL}^{-1}$.

\subsection{Polímeros de parede celular (PPC)}

A extração e determinação celulose e hemicelulose seguiu métodos gravimétricos. Para celulose adotou-se o método de Brendel, Losetta e Stewaart (2000). Em 100 mg do pó das amostras foi adicionado $2 \mathrm{~mL}$ de ácido de acético 80\% e $200 \mathrm{ml}$ de ácido nítrico 69\%. A mistura foi fervida em placa aquecedora por 1 h, e após esfriamento, adicionou-se etanol 99\% seguido de homogeneização, centrifugação e descartado o sobrenadante. O precipitado foi lavado sequencialmente em etanol 99\%, água deionizada, $\mathrm{NaOH}$ 17\%, água deionizada, água deionizada + ácido acético e água deionizada. Entre cada lavagem, as amostras foram centrifugadas e os sobrenadantes descartados. Após a última lavagem, o precipitado foi seco por $48 \mathrm{~h}$, pesado e o valor da pesagem subtraído do valor inicial da amostra. O resultado correspondente à fração da celulose.

As hemiceluloses foram determinadas pelo método de Schädel et al. (2010) sendo a extração enzimática do amido substituída pelo dimetilsulfóxido (DMSO) 90\% (CARPITA; KANABUS, 1987). De $50 \mathrm{mg}$ do pó das amostras foi extraído o amido. O precipitado livre de amido foi dissolvido em detergente neutro (tetraborato de sódio deca-hidrato, ácido etilenodiaminotetracético, sulfato de sódio dodecil, trietileno glicol, fosfato de sódio e água destilada) e fervido por 60 minutos em banho-maria. Nessa etapa se dá a extração de proteínas, carboidratos de baixo peso molecular, lipídios e pectinas, que foram separados por centrifugação e descartados. O precipitado 
contendo a fração da parede celular (celulose, hemiceluloses e lignina) foi lavado (água deionizada quente, acetona e água deionizada) e seco durante a noite e pesado no dia seguinte. O precipitado seco foi então dissolvido em detergente ácido contendo $\mathrm{H}_{2} \mathrm{SO}_{4} 1 \mathrm{~N}$ e brometo de cetiltrimetilamônio e fervido por 60 minutos para extração das hemiceluloses. A fração restante da parede celular (celulose e lignina) foi lavada com água deionizada e acetona, seguido de secagem e pesagem. As hemiceluloses foram determinadas gravimetricamente pela subtração da 'fração total da parede celular' menos 'fração de celulose e lignina'.

A lignina foi determinada pelo método de Dos Santos et al. (2008). De 150 mg do pó das amostras foram extraídas as proteínas com lavagem de diferentes soluções (tampão fosfato $50 \mathrm{mM} \mathrm{pH} \mathrm{7,} \mathrm{Triton}{ }^{\circledR} \times \mathrm{pH} 7$, tampão $\mathrm{NaCl} p H$ 7, água destilada e acetona) intercaladas por centrifugação. O sobrenadante foi descartado e o precipitado (fração de parede celular livre de proteínas) foi seco. Deste, utilizaramse $50 \mathrm{mg}$ que foi homogeneizado com ácido tioglicólico e $\mathrm{HCl} 2 \mathrm{M}$ seguido de fervura, centrifugação e lavagem com água destilada. Ao precipitado foi adicionado $\mathrm{NaOH}$ $0,5 \mathrm{M}$, incubado em $30^{\circ} \mathrm{C}$ por $18 \mathrm{~h}$ sob agitação constante, centrifugado e reservado o sobrenadante. O precipitado foi lavado com $\mathrm{NaOH} 0,5 \mathrm{M}$ e o sobrenadante reunido ao anterior que após acidificado com $\mathrm{HCl}$ foi mantido em $4^{\circ} \mathrm{C}$ por $12 \mathrm{~h}$. O homogeneizado foi centrifugado, o sobrenadante foi descartado e o precipitado foi lavado com água destilada, sendo depois seco e ressuspendido em $\mathrm{NaOH} \mathrm{0,5}$ M. O homogeneizado foi lido em espectrofotômetro (Genesys 10S UV-Vis, Thermo Fisher Scientific, Waltham, USA) 280 nm e a absorbância aplicada na curva padrão da solução de lignina (Sigma-Aldrich ${ }^{\circledR}$ ) de 0-500 $\mu \mathrm{g} / \mu \mathrm{L}$.

\subsection{Análise estatística}

O delineamento foi inteiramente casualizado em esquema fatorial $3 \times 2$ (morfotipos x irradiância solar). Os dados foram submetidos ao software estatístico InfoStat (Versão 2018, Grupo InfoStat, FCA, Universidade Nacional de Córdoba, Argentina) para análise de distribuição de normalidade com o teste de ShapiroWilk e variância (two-way ANOVA). As médias de $n=10$ foram comparadas pelo teste de Tukey $(P<0,05)$. 


\section{RESULTADOS E DISCUSSÃO}

\subsection{Crescimento e trocas gasosas}

No pleno sol, os três morfotipos cresceram expressivamente em comprimento e diâmetro do caule (Figura 1a-b). Comparando-se os morfotipos dentro de cada tratamento, no pleno sol, os morfotipos médio e grande cresceram mais em altura e diâmetro do caule do que o morfotipo pequeno. Na sombra, o morfotipo pequeno cresceu mais em comprimento em relação aos outros dois morfotipos. Ainda nesse tratamento, o diâmetro do caule não variou entre os três morfotipos.

Figura 1 - Medidas de altura e diâmetro do caule de plantas dos três morfotipos de Paubrasilia echinata cultivados por 12 anos na sombra ( - ) e no pleno sol ( $\square$ )

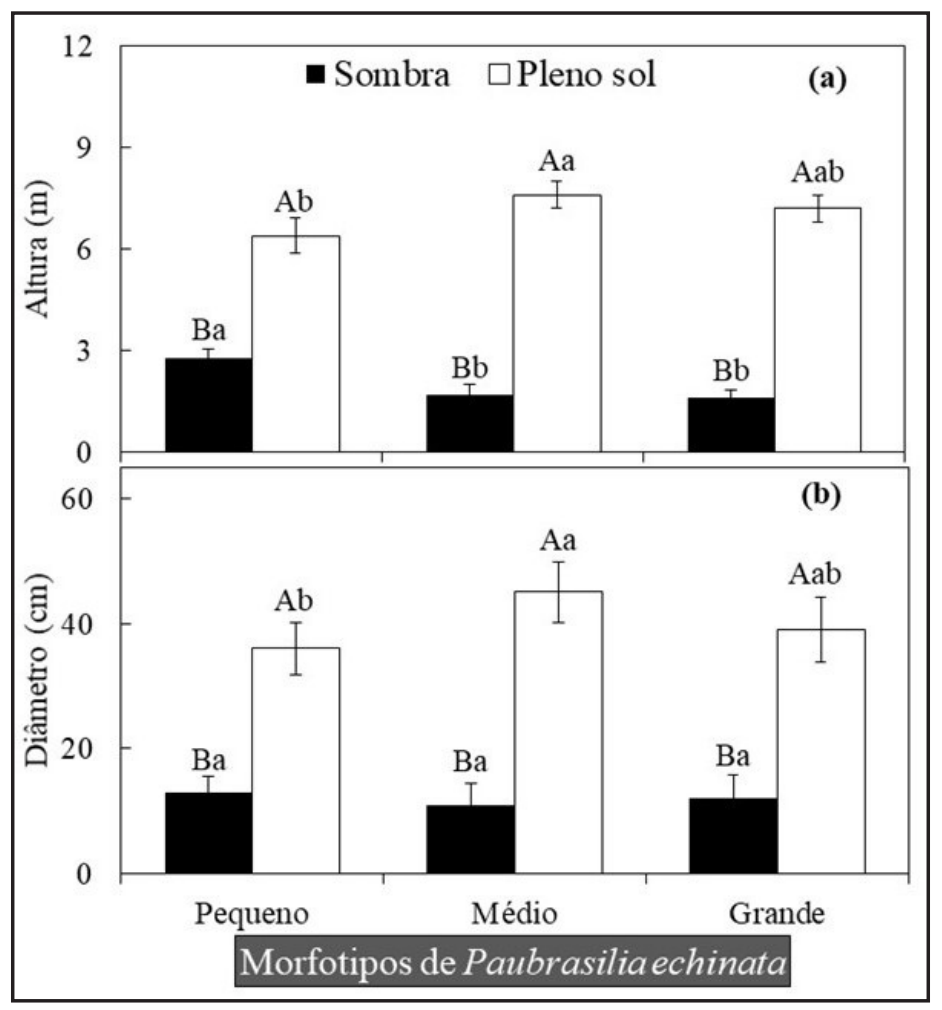

Fonte: Autores (2020)

Em que: A barra vertical representa o erro padrão da média $(n=10)$. Letras maiúsculas comparam os tratamentos dentro de cada morfotipo, e as letras minúsculas comparam os três morfotipos dentro de cada tratamento pelo teste de Tukey $(P<0,05)$. 
De modo geral, os tratamentos influenciaram consideravelmente nas variáveis das trocas gasosas dos três morfotipos (Figura 2a-d). Em pleno sol, os três morfotipos exibiram maiores taxas de assimilação líquida de $\mathrm{CO}_{2}(A)$, transpiração $(E)$ e condutância estomática (gs). A concentração intercelular de $\mathrm{CO}_{2}\left(C_{i}\right)$ dos morfotipos pequeno e grande também mostraram maiores valores em pleno sol, enquanto no morfotipo médio, essa variável não diferenciou entre os tratamentos. Quanto à EUA, os morfotipos pequeno e médio mostraram maiores valores na sombra, e o morfotipo grande no pleno sol (Figura 2e). Comparando-se os três morfotipos dentro de cada tratamento, em pleno sol, os morfotipos médio e grande apresentaram maiores valores de $A$, gs, E e EUA (Figura 2a, c-e), e o morfotipo pequeno, maiores valores de Ci (Figura 2b). Na sombra, os morfotipos médio e grande também apresentaram maiores valores de $A$, gs e $E$ em relação ao morfotipo pequeno. Ainda nesse tratamento, os morfotipos pequeno e médio expressaram maiores valores de EUA (Figura 2e). Quanto à Ci, seus valores na sombra não variaram entre os três morfotipos (Figura 2b).

O crescimento do caule e a assimilação do carbono são grandes ajustes morfológicos e fisiológicos de arbóreas tropicais frente às variações da irradiância (SOUZA; VÁLIO, 2003; BARROS et al., 2012; GAMA et al., 2019; PORTELA et al., 2019). Nesse sentido, o alongamento do caule e maior $A$ dos morfotipos em pleno sol confirma o hábito de tolerância ao pleno sol dos morfotipos médio e grande na fase inicial do crescimento (GAMA et al., 2019). Diferentemente do esperado, o morfotipo pequeno perdeu sua tolerância à sombra (MENGARDA et al., 2009; GAMA et al., 2019) e passou a manifestar tolerância ao pleno sol nos indivíduos adultos do presente estudo. Essa resposta pode ser atribuída às profundas mudanças morfológicas, fisiológicas e bioquímicas que ocorrem ao longo da ontogenia (ZANI et al., 2017). Talvez por isso, o morfotipo pequeno tenha crescido menos no pleno sol em relação aos outros dois morfotipos. A conservação do hábito heliófilo dos morfotipos médio e grande com o avanço da ontogenia parece ser determinado geneticamente por motivos desconhecidos. A falta de conexão do diâmetro do caule com os hábitos dos três morfotipos reforça a informação da inexistência de relação desta variável com os hábitos de espécies tropicais sob irradiância contrastante (GABURRO et al., 2015). 
Figura 2 - Assimilação de $\mathrm{CO}_{2}(A)$, condutância estomática (gs), transpiração $(E)$, concentração interna de $\mathrm{CO}_{2}(C i)$ e eficiência do uso da água (EUA) dos três morfotipos de Paubrasilia echinata cultivados por 12 anos na sombra ( $\mathbf{a}$ ) e no pleno sol ( $\square$ )

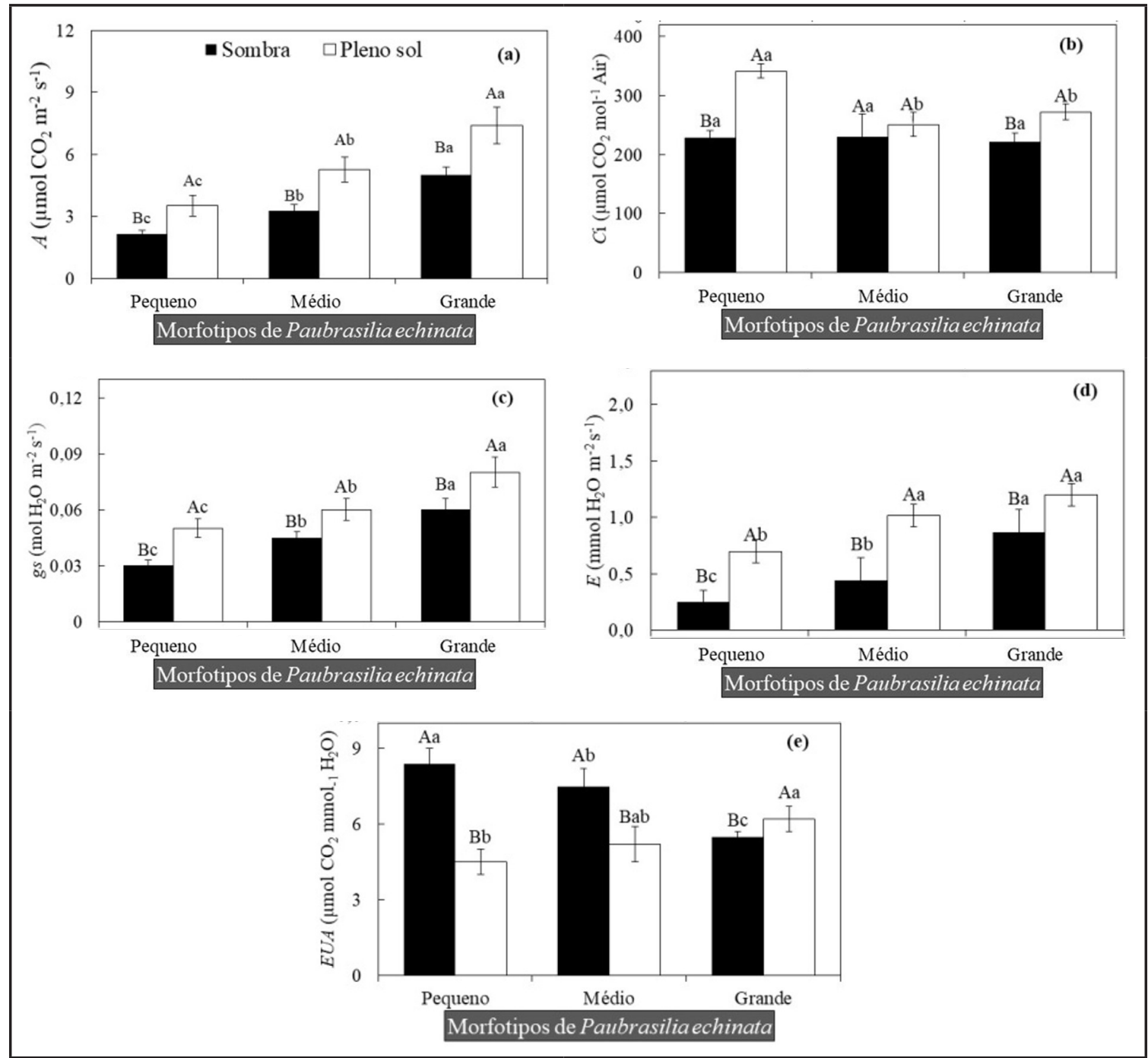

Fonte: Autores (2020)

Em que: A barra vertical representa o erro padrão da média $(n=10)$. Letras maiúsculas comparam os tratamentos dentro de cada morfotipo, e as letras minúsculas comparam os três morfotipos dentro de cada tratamento pelo teste de Tukey $(P<0,05)$.

Assim como observado nos morfotipos médio e grande, a gs e a $E$ do morfotipo pequeno também foram estimuladas pelo pleno sol. A maior perda de água por transpiração estomatal $(E)$ em pleno sol refletiu na maior EUA do morfotipo pequeno na sombra e do morfotipo grande no pleno sol. Já no morfotipo médio, maior EUA ocorreu em plantas adultas no pleno sol. Com exceção do morfotipo médio, os resultados são 
consistentes com a informação de que espécies tropicais heliófilas são mais eficazes na EUA do que espécies ombrófilas quando submetidas a ambientes altamente iluminados (SIEGERT; LEVIA, 2011). Esses resultados são consistentes, também, com a maior EUA do morfotipo médio em pleno sol (GAMA et al., 2019; CUZZUOL et al., 2020) e do morfotipo pequeno na sombra (MENGARDA et al., 2009; GAMA et al., 2019; CUZZUOL et al., 2020).

\subsection{Carboidratos não estruturais-CNE (açúcares solúveis + amido)}

Em uma visão geral, os teores desses compostos (folhas e caule) dos três morfotipos exibiram maiores valores em pleno sol (Figura 3a-f). Dos CNE, somente o amido foliar do morfotipo pequeno não mostrou influência dos tratamentos (Figura 3e). Comparando-se os três morfotipos dentro de cada tratamento, de maneira geral, os morfotipos médio e grande mostraram-se mais enriquecidos em CNE, açúcares solúveis e amido, tanto em pleno sol como na sombra (Figura 3a-f). Em uma análise qualitativa, nota-se ligeira superioridade das folhas dos três morfotipos em acumular CNE e açúcares solúveis em relação ao caule (Figura 3a-f). Especialmente no pleno sol. Com relação ao amido, o caule mostrou teores superiores desse polissacarídeo em relação às folhas (Figura 3e-f). Transformando os dados em \% de m.s. (dados não apresentados), os CNE representam 8-14 \% m.s., sendo 5-11 \% constituídos de açúcares solúveis e 2-4 \% de amido (Figura 3e-f), com pequenas variações entre folhas e caule.

A maior assimilação do $\mathrm{CO}_{2}$ dos três morfotipos no pleno sol refletiu em maiores concentrações de açúcares solúveis (folhas e caule) nessa irradiância. Esses resultados confirmam a existência da relação positiva entre a atividade da fotossíntese e os teores de açúcares (GABURRO et al., 2015; HARTMANN; TRUMBORE, 2016; MARTÍNEZ-VILALTA et al., 2016). Além de fonte energética, os açúcares desempenham importante papel fisiológico na tolerância à elevada irradiância na qual podem atuar como inibidores das reações oxidantes (MENGARDA et al., 2012; GAMA et al., 2019) e promotores da turgescência do mesofilo por mecanismos de osmorregulação (SALA; MENCUBCINI, 
2014; GAMA et al., 2019). O acúmulo de amido (folhas e caule) dos três morfotipos em pleno sol parece ter relação com os maiores teores de açúcares solúveis. Essa possibilidade é amparada pela informação de que os fotossintatos excedentes, e não utilizados no crescimento e respiração celular, são armazenados na forma de amido transitório (HARTMANN; TRUMBORE, 2016; MARTÍNEZ-VILALTA et al., 2016).

Figura 3 - Concentrações dos carboidratos não estruturais-CNE (açúcares solúveis e amido) em folhas e caule de plantas dos três morfotipos de Paubrasilia echinata cultivados por 12 anos na sombra ( $\square$ ) e no pleno sol ( $\square$ )

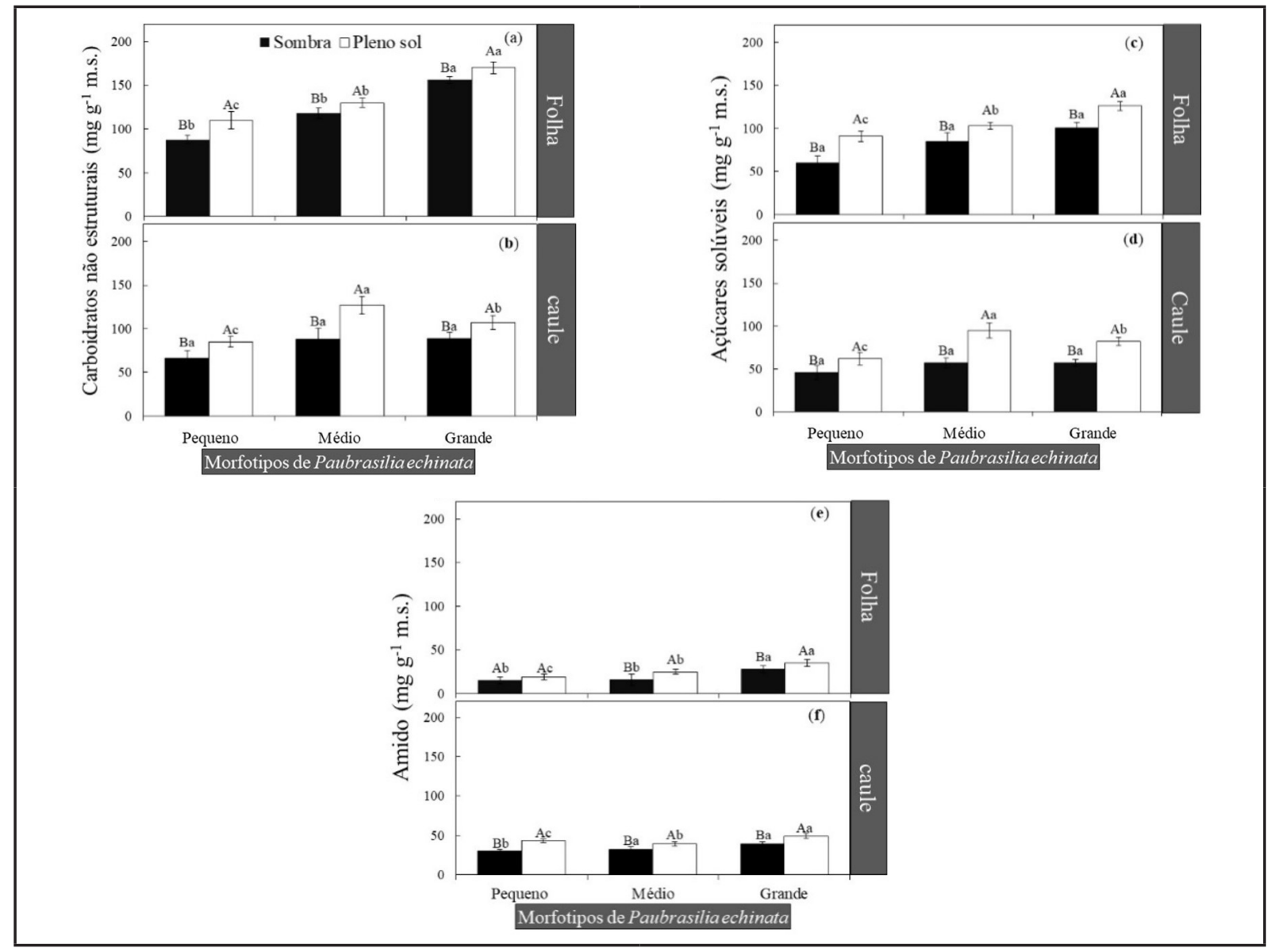

Fonte: Autores (2020)

Em que: A barra vertical representa o erro padrão da média $(n=10)$. Letras maiúsculas comparam os tratamentos dentro de cada morfotipo, e as letras minúsculas comparam os três morfotipos dentro de cada tratamento pelo teste de Tukey $(P<0,05)$.

Como esperado, os teores de açúcares solúveis foliares se mostraram superiores aos teores no caule. Essa maior força da fonte em relação ao dreno corrobora 
a informação de que folha é o órgão de maior atividade metabólica (MARTíNEZVILALTA et al., 2016). O superior teor de açúcares solúveis dos três morfotipos em pleno sol apoia o critério de utilização dos teores desses compostos como métrica de classificação do hábito de espécies florestais (LI et al., 2016). Reforçando essa ideia, em arbóreas adultas da floresta tropical Macieira et al. (2020) constataram teores de açúcares solúveis $\geq 15 \%$ m.s. caulinar em espécies ombrófilas (não pioneiras) e menor que isso em espécies heliófilas (pioneiras). Essas informações confirmam o hábito heliófilo dos três morfotipos adultos ao apresentarem teores de açúcares solúveis $\leq$ $11 \%$ m.s. caulinar.

\subsection{Polímeros de Parede Celular-PPC (celulose, hemicelulose e lignina)}

Diferenças entre os tratamentos ocorreram nos teores das hemiceluloses (caule) e lignina (folha e caule), mas não com nos teores de celulose (Figura 4a-f). O pleno sol elevou o teor das hemiceluloses caulinar dos morfotipos médio e grande (Figura 4d) e de lignina (folhas e caule) dos três morfotipos (Figura 4e-f). Comparando os PPC das folhas dos três morfotipos dentro de cada tratamento, somente a celulose e hemiceluloses mostraram diferenças com o morfotipo pequeno se destacando com maiores valores (Figura 4a,c). No pleno sol, os teores dos PPC das folhas dos três morfotipos não variaram entre si (Figura 4a, c, e). Com relação ao caule, as diferenças foram bem expressivas entre os três morfotipos dentro de cada tratamento. Se por um lado o caule do morfotipo pequeno se destacou pelo maior teor de celulose (Figura 4b), por outro, o caule dos outros dois morfotipos exibiram maiores valores de hemiceluloses dentro de cada tratamento (Figura 4d), e de lignina no pleno sol (Figura 4f). Comparando-se qualitativamente os órgãos vegetais, o caule dos três morfotipos mostraram teores dos PPC superiores aos das folhas (Figura 4a-f). Transformando os teores dos PPC em percentual de massa seca (dados não apresentados), de maneira geral, em folhas, o teor de cada PPC representou 10\% m.s. Quando reunidos, corresponderam a 30\% m.s. Já no caule, cada PPC correspondeu a 27\% m.s. e quando reunidos, $\sim 80 \%$ m.s. 
Figura 4 - Concentrações de polímeros de parede celular (celulose, hemiceluloses e lignina) em folhas e caule de plantas de três morfotipos de Paubrasilia echinata cultivados por 12 anos na sombra ( $\mathbf{~ a ~ ) ~ e ~ n o ~ p l e n o ~ s o l ~ ( ~} \square$ )

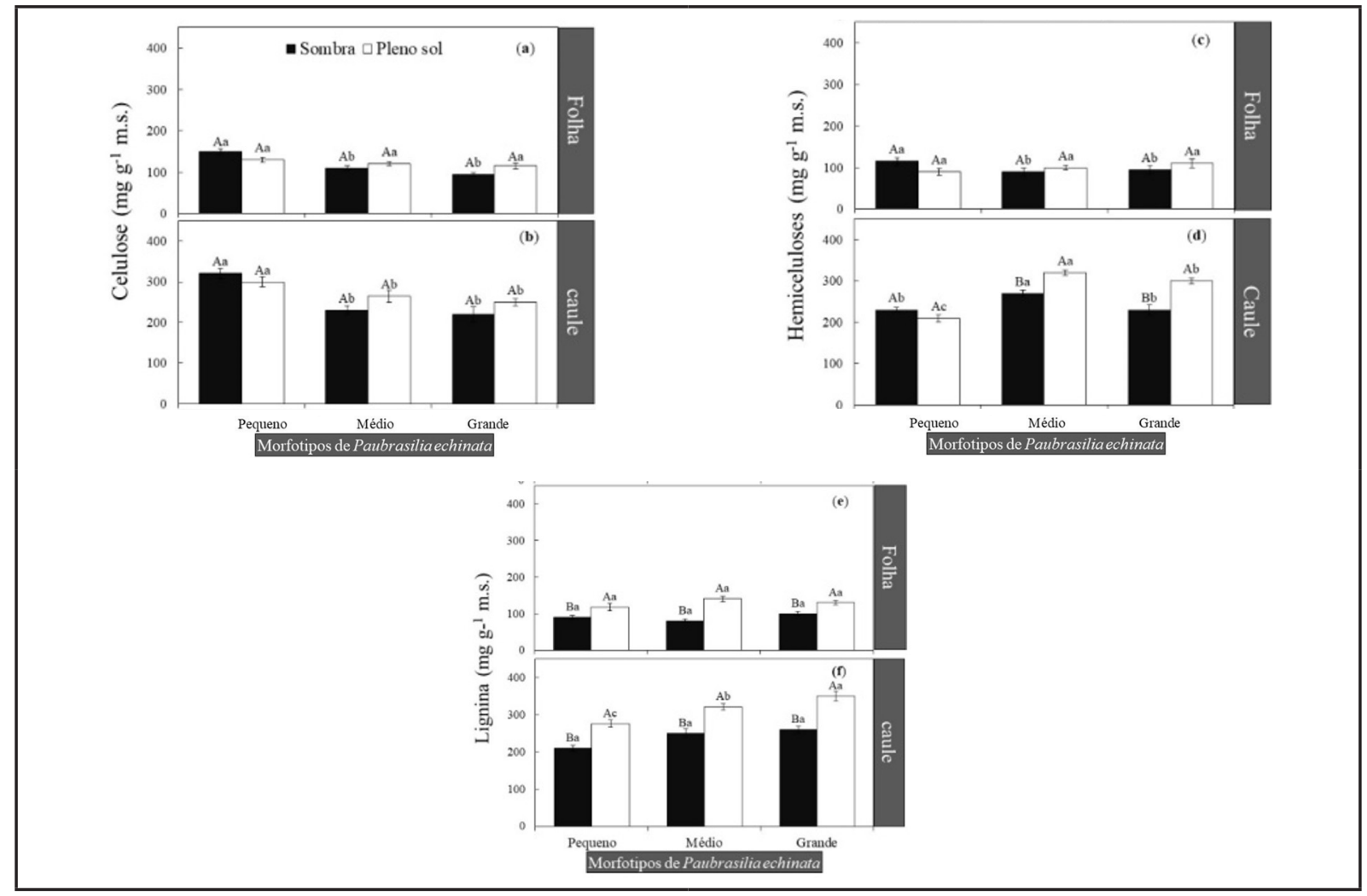

Fonte: Autores (2020)

Em que: A barra vertical representa o erro padrão da média $(n=10)$. Letras maiúsculas comparam os tratamentos dentro de cada morfotipo, e as letras minúsculas comparam os três morfotipos dentro de cada tratamento pelo teste de Tukey $(P<0,05)$.

Considerando-se que parte dos açúcares solúveis entra na rota de síntese de polímeros de parede celular (HARTMANN; TRUMBORE, 2016), maiores teores desses compostos eram esperados no pleno sol. No entanto, isso só foi observado nos teores de hemiceluloses caulinar dos morfotipos médio e grande, e de lignina foliar e caulinar dos três morfotipos. Esses resultados sugerem melhor qualidade do caule desses dois morfotipos em relação ao morfotipo pequeno, no pleno sol, pois a maior deposição desses PPC está associada ao aumento da dureza da madeira (ZANI et al., 2017). A falta de diferença significativa dos teores de celulose (folha e caule) dos três morfotipos entre as irradiâncias contrastanes confirma a forte resiliência deste PPC às variações 
ambientais (LE GALL et al., 2015). Outra causa da ausência de variação da celulose foliar, bem como das hemiceluloses foliares dos três morfotipos entre os tratamentos, pode ser atribuída à baixa proporção destes PPC em folhas desprovidas de parede celular secundária (MACIEIRA et al., 2020). Os maiores teores das hemiceluloses caulinares dos morfotipos médio e grande em pleno sol confirmam a informação de que a maior irradiância estimula o aumento do teor destes PPC (LE GALL et al., 2015). A ausência de diferença significativa das hemiceluloses caulinar do morfotipo pequeno entre as irradiâncias contrastantes parece ser uma característica intraespecífica deste morfotipo. A maior lignificação (folhas e caule) dos três morfotipos em pleno sol ratifica a relação positiva da intensidade da irradiância com a deposição de lignina em tecidos vegetais (LE GALL et al., 2015) a qual funciona como isolante térmico à elevação da temperatura associada à maior luminosidade (AKGÜL; ÇÖPÜR; TEMIZ, 2007).

No presente estudo, a lignificação caulinar se manifestou de forma mais expressiva nos morfotipos médio e grande. Essa resposta pode ser atribuída ao hábito heliófilo desses dois morfotipos iniciada na fase juvenil (GAMA et al., 2019; CUZZUOL et al., 2020), e continuada na fase adulta do presente estudo. Os superiores teores das hemiceluloses e lignina caulinar dos três morfotipos adultos em relação à fase juvenil (GAMA et al., 2019; CUZZUOL et al., 2020), em pleno sol, confirma a informação de que a lignificação de Paubrasilia echinata aumenta com o avanço da ontogenia (ZANI et al., 2017). Além do fator ambiental (irradiância), a maior lignificação caulinar dos morfotipos médio e grande no pleno sol, em relação ao morfotipo pequeno, parece ter relação com os teores de amido. Para Poorter e Kitajima (2007) e Novaes et al. (2010), a tolerância ao pleno sol (hábito heliófilo) consiste na capacidade da planta acumular amido em ambientes mais iluminados. Com isso, o maior teor de amido caulinar dos morfotipos médio e grande no pleno sol deve ter impulsionado mais síntese de lignina em caules desses dois morfotipos em relação ao morfotipo pequeno. 


\section{CONCLUSÕES}

Concluiu-se que, na fase adulta, os três morfotipos mostraram hábito heliófilo, indicado pelo maior crescimento do comprimento do caule e $A$ em pleno sol. Esses resultados foram corroborados pelos maiores teores de açúcares solúveis, amido, hemiceluloses e lignina. Porém, com maior acúmulo no caule dos morfotipos médio e grande adultos cultivados no pleno sol. A celulose mostrou-se indiferente aos tratamentos. Sabendo-se do papel das hemiceluloses e da lignina na qualidade da madeira, sugerimos os morfotipos médio e grande cultivados em pleno sol para o florestamento comercial. Porém, dentre esses dois, o morfotipo grande parece ser o mais indicado por apresentar maior lignificação caulinar.

\section{AGRADECIMENTOS}

Este estudo foi financiado pela Fundação de Pesquisa e Inovação do Espírito Santo-FAPES do Brasil (Proc. 207/2017). Os três primeiros autores agradecem a Coordenação de Aperfeiçoamento de Pessoal de Nível Superior - CAPES pela concessão de bolsa de estudo. Agradecemos à empresa Marco Raposo Bows pela disponibilização da área plantada de pau-brasil para realização deste estudo.

\section{REFERÊNCIAS}

AKGÜL, M.; ÇÖPÜR, Y.; TEMIZ, S. A comparison of kraft and kraft-sodium borohydratebrutia pine pulps. Building and Environment, Oxford, v. 42, p. 2586-2590, 2007.

AMARAL, L. I. V. et al. A new rapid and sensitive enzymatic method for extraction and quantification of starch in plant material. Hoehnea, São Paulo, v. 34, p. 425-431, 2007.

ANGYALOSSY, V.; AMANO, E.; ALVES, E. S. Madeiras utilizadas na fabricação de arcos para instrumentos de corda: aspectos anatômicos. Acta Botanica Brasilica, São Paulo, v. 19, n. 4, p. 819-834, 2005.

BARROS, F. de V. et al. Phenotypic plasticity to light of two congeneric trees from contrasting habitats: Brazilian Atlantic Forest versus cerrado (savanna). Plant Biology, Stuttgart, v. 14, p. 208-215, 2012. 
BRENDEL, O.; LOSETTA, P. P. M. G.; STEWAART, D. A rapid and simple method to isolate pure alpha cellulose. Phytochemical Analysis, Sessex, v, 11, p. 7-10, 2000.

CARPITA, N. C.; KANABUS, J. Extraction of starch by dimethyl sulfoxide and quantitation by enzymatic assay. Analytical Biochemistry, New York, v. 161, p. 132-139, 1987.

CARPITA, N. C.; MCCANN, M. The cell wall. In: BUCHANAN, B. B.; GRUISSEM, W.; JONES, R. L. (ed.). Biochemistry and molecular biology of plants. Rockville: American Society of Plant Biologists, 2000. p. 52-108.

CESARINO, I. Structural features and regulation of lignin deposited upon biotic and abiotic stresses. Current Opinion in Biotechnology, London, v. 56, p. 209-214, 2019.

CUZZUOL, G. R. F.et al. UV-B effects on growth, photosynthesis, total antioxidant potential and cell wall components of shade-tolerant and sun-tolerant ecotypes of Paubrasilia echinata. Flora, [s. I.], v. 271, p. 151679, 2020.

DOS SANTOS, W. D. et al. Soybean (Glycine max) root lignification induced by ferulic acid. The possible mode of action. Journal of Chemical Ecology, New York, v. 34, p. 1230-1241, 2008.

EBRINGEROVA, A.; HROMADKOVA, Z.; HEINZE, T. Hemicellulose. Polysaccharides 1: Structure, Characterization and Use. Berlin: Springer-Verlag, 2005. p. 1-67.

GABURRO, T. A. et al. Physiological variables related to photosynthesis are more plastic than the morphological and biochemistry in non-pioneer tropical trees under contrasting irradiance. Brazilian Journal of Botany, São Paulo, v. 38, n. 1, p. 39-49, 2015.

GAMA, V. N. et al. Eophyiological responses of medium morphotype plants of Paubrasilia echinate raised under full sunlight and natural shade. Revista Árvore, Viçosa, MG, v. 43, n. 4, e430407, 2019.

HARTMANN, H.; TRUMBORE, S. Understanding the roles of nonstructural carbohydrates in forest trees - from what we can measure to what we want to know. New Phytologist, Cambridge, v. 211, n. 2, p. 386-403, 2016.

INSTITUTO CAPIXABA DE PESQUISA E ASSISTÊNCIA TÉCNICA E EXTENSÃO RURAL. Boletim meteorológico de Vitória e Domingos Martins. Vitória, 2018. Disponível em: https:// meteorologia.incaper.es.gov.br/boletim-agrometeorologico. Acesso em: 03 set. 2018.

JUCHUM, F. S. et al. Phylogenetic relationships among morphotypes of Caesalpinia echinata Lam. (Caesalpinioideae: Leguminosae) evidenced by trnL intron sequences. Naturwissenschaften, [s. I.], v. 95, p. 1085-1091, 2008.

KÖPPEN, W. Climatologia: com unestudio de los climas de latierra. México: Fondo de Cultura Economica, 1948. 478 p.

LE GALL, H. et al. Cell wall metabolism in response to abiotic stress. Plants, [s. I.], v. 4, p. 112166, 2015. 
LOBO, F. de A. et al. E. Fitting net photosynthetic light-response curves with Microsoft Excel - a critical look at the models. Photosynthetica, Prague, v. 51, p. 445-456, 2013.

LI, N. et al. Leaf non-structural carbohydrates regulated by plant functional groups and climate: evidences from a tropical to cold-temperate forest transect. Ecological Indicators, [s. I.], v. 62, p. 22-31, 2016.

LIU, $Y$ et al. Irradiation pretreatment facilitates the achievement of high total sugars concentration from lignocellulose biomass. Bioresource Technology, Essex, v. 232, p. 270277, 2017.

LUSK, C. H. et al. Why are evergreen leaves so contrary about shade? Trends in Ecology \& Evolution, Amsterdam, v. 23, n. 6, p. 299-303, 2008.

MACIEIRA, B. P. B. et al. Stem and leaf functional traits allow successional classification in six pioneer and non-pioneer tree species in Tropical Moist Broadleaved Forests. Ecological Indicators, [s. I.], v. 113, p. 106254, 2020.

MARTÍNEZ-VILALTA, J. et al. Dynamics of non-structural carbohydrates in terrestrial plants: a global synthesis. Ecological Monographs, [s. I.], v. 86, n. 4, p. 495-516, 2016.

MCDOWELL, N. G.; FISHER, R.; XU, C. Uncertainties and opportunities in modeling droughtassociated vegetation mortality. New Phytologist, Cambridge, v. 200, p. 304-321, 2013.

MENGARDA, L. H. G. et al. Light as an indicator of ecological succession in brazilwood (Caesalpinia echinata Lam.). Brazilian Journal of Plant Physiology, Campinas, v. 21, p. 55-64, 2009.

MENGARDA, L. H. G. et al. Morphological and physiological adjustments of brazilwood (Caesalpinia echinata Lam.) to direct solar radiation. Brazilian Journal of Plant Physiology, Campinas, v. 24, n. 3, p. 161-172, 2012.

NOVAES, E. et al. Lignin and biomass: a negative correlation for wood formation and lignin content in trees. Plant Physiology, [s. I.], v. 154, p. 555-561, 2010.

POLLOCK, C. J. Fructans and the metabolism of sucrose in vascular plants. New Phytologist, Cambridge, v. 104, p. 1-24, 1986.

POORTER, L.; KITAJIMA, K. Carbohydrate storage and light requirements of tropical moist and dry forest tree species. Ecology, [s. I.], v. 88, n. 4, p. 1000-1011, 2007.

PORTELA, F. C. S. et al. How does Cariniana estrellensis respond to different irradiance levels? Journal of Forestry Research, Colombo, v. 30, n. 1, p. 31-44, 2019.

RICHARDSON, A. D. et al. Seasonal dynamics and age of stem wood nonstructural carbohydrates in temperate forest trees. New Phytologist, Cambridge, v. 197, p. 850-861, 2013.

SALA, A.; MENCUCCINI, M. Ecosystem science: plump trees win under drought. Nature Climate Change, [s. I.], v. 4, p. 666-667, 2014. 
SCHÄDEL, C. et al. Quantification and monosaccharide composition of hemicelluloses from different plant functional types. Plant Physiology and Biochemistry, [s. I.], v. 48, n. 1, p. 1-8, 2010.

SENDALL, K. M.; LUSK, C. H.; REICH, P. B. Becoming less tolerant with age: sugar maple, shade, and ontogeny. Oecologia, Berlin, v. 179, n. 4, p. 1011-1021, 2015.

SIEGERT, C. M.; LEVIA, D. F. Stomatal conductance and transpiration of co-occurring seedlings with varying shade tolerance. Trees, [s. I.], v. 25, n. 1091-1102, 2011.

SOUZA, R. P.; VALIO, I. F. M. Seedling growth of fifteen Brazilian tropical tree species differing in successional status. Brazilian Journal of Botany, São Paulo, v. 26, p. 35-47, 2003.

ZANI, L. B. et al. The vessel elements and hemicelluloses as the most plastic structural components of the brazilwood ontogeny (Caesalpinia echinata Lam.) medium morphotype. Brazilian Journal of Botany, São Paulo, v. 40, n. 3, p. 793-800, 2017.

\section{Contribuição de Autoria}

\section{1 - Carlos Augusto Pagotto Martins}

Biólogo, Me., Doutorando

https://orcid.org/0000-0002-2899-7768•augustopmartins@hotmail.com

Contribuição: Metodologia, Análise Formal, Escrita - primeira redação, Software, Visualização de dados

\section{2 - Vinicius Novo Gama}

Biólogo, Dr., Professor Voluntário

https://orcid.org/0000-0002-1165-3547• viniciusnovogama@gmail.com

Contribuição: Metodologia, Análise Formal, Escrita - primeira redação, Software, Visualização de dados

\section{3 - Fabiano Caprini Volponi}

Biólogo, Me., Doutorando

https://orcid.org/0000-0003-0453-9444•caprinivolponi@gmail.com

Contribuição: Metodologia, Investigação, Software 


\section{4 - Bernardo Pretti Becacici Macieira}

Biólogo, Dr., Professor Voluntário

https://orcid.org/0000-0001-8283-2334• bernardopretti@gmail.com

Contribuição: Escrita - primeira redação, Visualização de dados, Análise Formal, Escrita - revisão e edição

\section{5 - Geraldo Rogério Faustini Cuzzuo}

Biólogo, Dr., Professor

https://orcid.org/0000-0002-2055-492X·gcuzzuol@gmail.com

Contribuição: Supervisão, Obtenção de financiamento, Administração do projeto, Recursos, Escrita - revisão e edição

\section{Como citar este artigo}

Martins, C. A. P.; Gama, V. N.; Volponi, F. C.; Macieira, B. P. B.; Cuzzuo, G. R. F. Intensidade da irradiância no fluxo e alocação do carbono em árvores adultas de três morfotipos de Paubrasilia echinata. Ciência Florestal, Santa Maria, v. 31, n. 3, p. 1472-1493, 2021. DOI 10.5902/1980509844291. Disponível em: https://doi.org/10.5902/1980509844291. Acesso em: xx mês-abreviado. 2021. 